\title{
辨认前寒武纪变质岩系中 褔皱构造形迹的实例
}

袁 海广

(中国地质科学院)

众所周知, 鞍山式铁矿赋存在前寒武纪变质岩系地层里. 前寒武纪变质铁矿和富铁矿的 储量大约都占世界总储量的 $70 \%$ 。在我国, 这类铁矿也占有很重要的比例. 因而, 依靠地表 工作查明前寒武纪变质岩系的褶皱形迹, 从而确定这类沉积或火山沉积变质铁矿体的空间分 布规律, 是地质工作者的一个重要课题. 这对恢复和建立前寒武纪地层层序以及快速扩大已 知矿区的储量并进一步指出找矿方向, 都有比较重要的意义.

\section{一、沙厂铁矿揌鲏构造的研究及证实}

沙厂铁矿, 赋存在前震旦纪片麻岩系中, 前人多认为是单斜. 1962-1963 年, 我们两次参 加该矿区二千分之一的地质填图, 并对该矿区的基底构造进行了较详细的地表研究工作. 由 于该矿区的磁性强, 罗盘失灵, 1962 年我们使用自己设计制造的日光罗盘, 测量了几百个片 理和线理的产状, 素描了几十个层中拖褔皱(包括向斜转折端紧密排列的相似槢皱)和一些“古 辟理”,找到了铁山头向斜在平面上的转折端，参考了已有的两、三个钻孔资料，并结合对该矿 区磁测平剖图的解释，肯定该矿区 I-II 矿带间构成一个背斜 (即铁东背斜), II-III 矿带间构 成一个向斜 (即铁山头向斜*)，III-IV 矿带间是背斜 (即铁西背斜*)，而 IV 矿带自身构成一 个向斜**.

为了给矿区勘探提供依据，我们还利用地表资料重点解剖了铁山头向斜的形态和矿体的 埋藏标高. 我们认为, 向斜核部的矿层也会像铁山头一样,由于禇坡挤压重迭而大大加厚. 基 于上述认识, 陈光远教授曾向有关单位建议，钻孔布置在向斜核部可使储量增加几倍; 欲扩大 外围远景,需向东西方向找寻.

经过 101 队近几年的实践，重新查清了该矿区的褶铍构造，使铁矿储量翻了几翻，并在沙 厂以西找到了察家洼铁矿。

现把沙厂铁矿区褶坡构造证实情况初步对比如下:

1. 组成矿区的几个褶曲结论相同(见前述).

本文 1978 年 8 月 14 日收到。

- 这里采用 101 队 1976 年所用的名称。

**关于沙厂铁矿区的构造问题, 北京地质局物探队根据 1959-1963 年的磁法工作亦认为是袹铍构造,密伓平勘探队曾 同意上述观点. 1966-1967 年进行补充勘探,因钻孔浅,否定了褶皱构造. 1972 年进行磁法详査, 1976 年由 101 队 重新查明证实了该矿区的褶坡构造. 
2. 铁山头向斜核部确实存在厚大的盲矿体. 这是在变质作用中由于温度、压力使磁铁矿 层产生的塑性程度、层间拖电力和重力造成的. 就此而言, 背斜不如向斜, 加之背斜易被剥蚀, 所以向斜核部是最好的贮矿部位. 找这类铁矿应结合磁异常到向斜核部去找寻.

3. 推断的铁山头向斜形态与详细勘探的结果相近. 图 1 是笔者 1963 年根据地表资料结 合磁测剖面图，对铁山头向斜形态所做的定性解释图之一，该剖面位于向斜中部. 图 2 是 101 队于 1976 年经钻孔控制的 VII 勘探线剖面图. 两者位置相近, 形态相似.

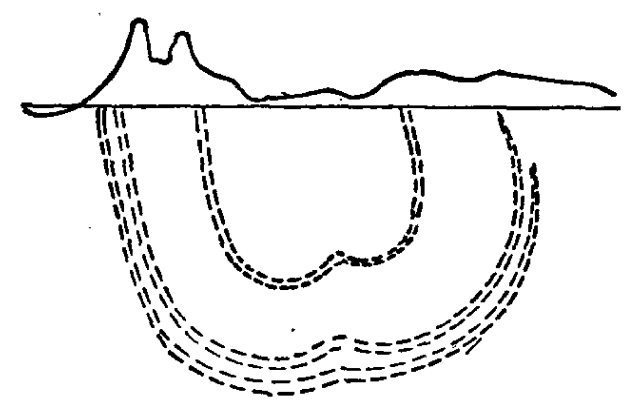

图 1 铁山头向斜形态定性解释图

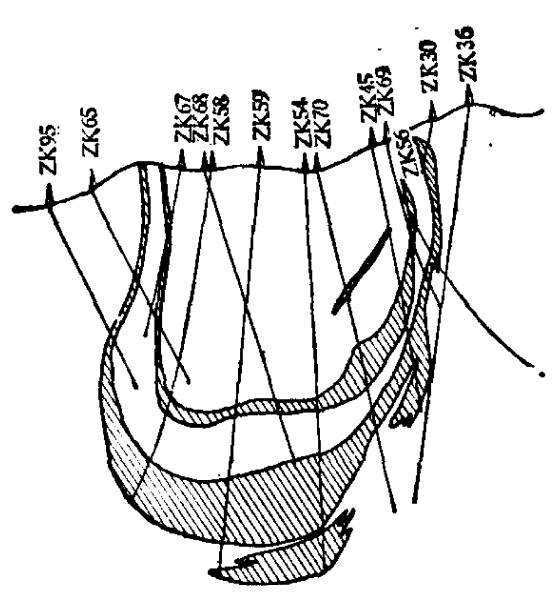

图 2 铁山头向斜 VII 勘探线剖面图

4. 铁山头向斜核部矿体向南倾没情况，勘探结果与当年用线理推算结果大体相符. 图 3 是铁山头向斜纵剖面推算矿体与勘探矿体符合示意图. 图中推算矿体的上层矿是根据矿体上 盘纵剖面附近的线理倾角绘制的; 下层矿是根据矿体下盘附近的线理倾角绘制的 (表 1). 图 中的勘探矿体是根据 101 队 1976 年勘探报告中所列的两层矿底板标高 (表 2) 绘制的. 下层 矿厚度采用 VII 线剖面中向斜核部的最小厚度. 可以看出, 下层矿由于线理太少, 误差稍大，

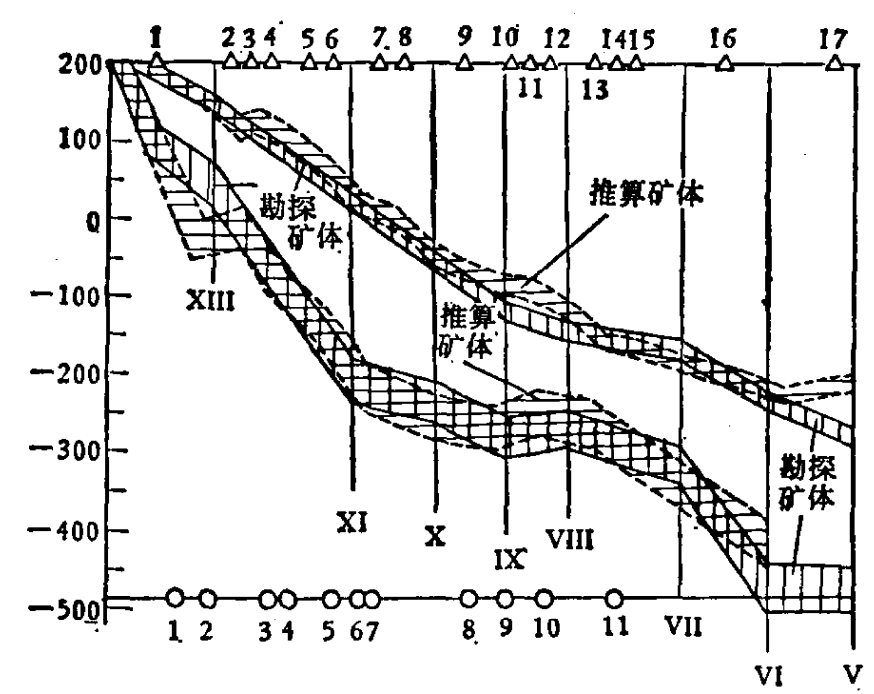

图 3 铁山头向斜纵剖面矿体符合示意图 
表 1 纵剖面附近线理数据

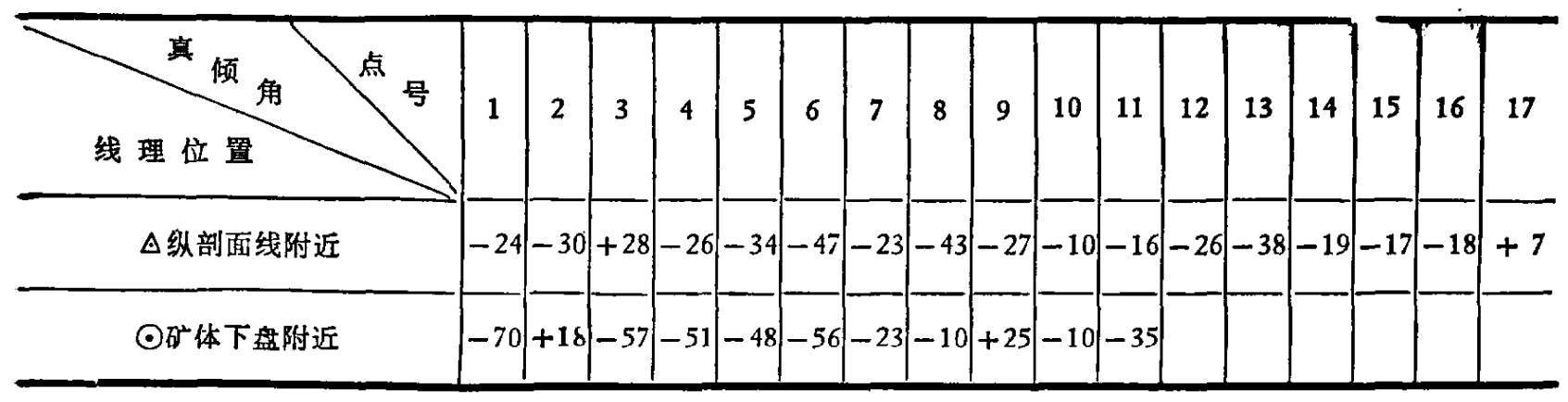

表 2 矿体底板标高 (米)

\begin{tabular}{c|c|c|c|c|c|c|c|c}
\hline 勘探线号 & $\mathrm{XIII}$ & $\mathrm{XI}$ & $\mathrm{X}$ & $\mathrm{IX}$ & $\mathrm{VIII}$ & $\mathrm{VII}$ & $\mathrm{VI}$ & $\mathrm{V}$ \\
\hline 上层 矿 & 144 & & -62 & -130 & -154 & -180 & -244 & -290 \\
\hline 下层 矿 & 12 & -232 & -260 & -309 & -292 & -340 & -505 & -502 \\
\hline
\end{tabular}

而上层矿符合较好,不少地段相一致,多数地段矿体底板标高只差一、二十米,只个别地方相差 四、五十米. 一般来讲, 地下的推算矿层的高程都比实际勘探结果稍高, 原因有四: (1) 后期 断层的影响；（2）上下线理产状上的差异；（3）走向上层中拖褶皱的影响；（4）我们所测的 线理没有完全在剖面线上.

以上对比说明在这些深变质岩地区, 依靠地表工作还是能够比较确切地辨认褶皱构造形 迹,进而大致圈定矿体在地下埋藏的空间分布规律的.

\section{二、对几种小型构造的认识和应用}

分析该矿区的褶皱构造时,我们在确定了地层对称的基础上,采用的是地表小型构造研究 和磁法图件分析相结合的方法. 磁法,早已被大家采用,不再整述. 这里只谈一下对几种小型 构造的认识和应用. 为了叙述简便, 我们常把片麻理简称为片理, 而把片理面称为 $s$ 面, 把平 行线理、垂直于 $S$ 面的面称为 $L$ 面, 把垂直于线理的面称为 $Q$ 面.

1. 层中拖褶皱的成因及其应用当前寒武纪地层遭受变质作用的时候, 由于温度、压力 较高, 原来岩石在常温常压下的一些物理性质就要发生改变,有些甚至从脆性转变成塑性. 因

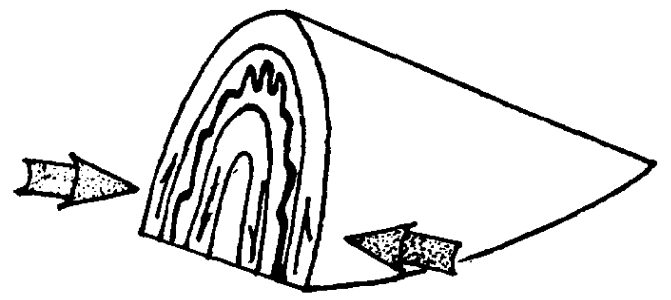

图 4 地层褶坡时塑性地层 形成层中拖褶皱示意图 而在力的作用下就会产生塑性形变. 石英磁铁矿层就 是其中之一. 当地层在强大水平压力的推动下发生褶 皱的时候,由于单层厚度的存在,层间必产生相对滑动. 对某一单层来讲,两侧就出现一对力偶, 这对力偶就拖 电塑性地层形成层中拖褟皱 (见图 4)，其特点是具有 明显的长、短边．若在 $s$ 面上则形成波状．抓住其长、 短边特点,即便磁铁矿不连续, 形不成明显的拖褶皱形

态, 也往往能够找到断续的长、短边, 帮我们进行力学 分析. 而当作用力更强烈的时候, 层中拖褔皱还可以如图 5 所示形成绳曲. 根据这些道理, 在 野外就可以用它来分析地层的受力方向, 推知比其大一级的褶曲形迹. 但要注意, 观察层中拖 
褶坡来分析褶坡时的应力场,需要在 $Q$ 面上进行.

2. 从 “古䢃理”的产生兼谈片麻理的形成

前寒武纪变质岩的片麻理是怎样形成的,有 待探讨. 而关于浅变质岩(板岩和千枚岩)片理的 成因(称为轴面片理), 存在两种不同的看法,一种 认为片理是平行于流动方向及垂直于主压力方向 生成的; 另一种认为片理一般是沿斜交主应力方 向的斜面上剪切作用的结果. 我们研究沙厂矿区 褶皱构造形迹的时候，发现黑云母斜长片麻岩和 角闪斜长片麻岩等在变质作用下相对脆性的地层

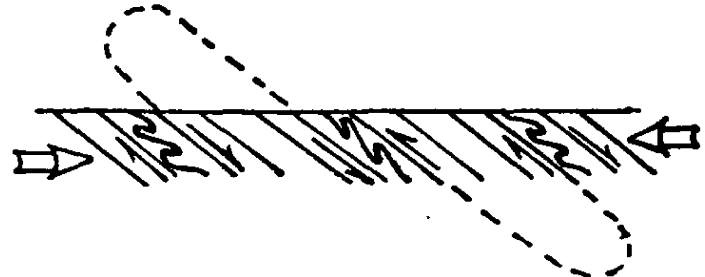

图 5 层中拖褶皱形成绳曲示意图 之 $Q$ 面上,出现的不是层中拖褶皱, 而是一些片麻理. 其与层理的关系只有在层理保存完好的 地方才能见到如图 6 所示. 我们认为这种片麻理是与褶皱同时形成的一组层间剪切䢃理面. 为 了跟变质以后的䢃理加以区别, 当时称之为“古擘理”。而形成它们的作用力, 不单是主压力, 也不单是层间滑动力, 而应是两者共同作用的结果. 常听说片麻理与层理大多数平行, 少数斜 交, 就是由于地表的观察往往限于 $L$ 面的结果. 只有褶曲的转折部位, $L$ 面上才会出现两者的

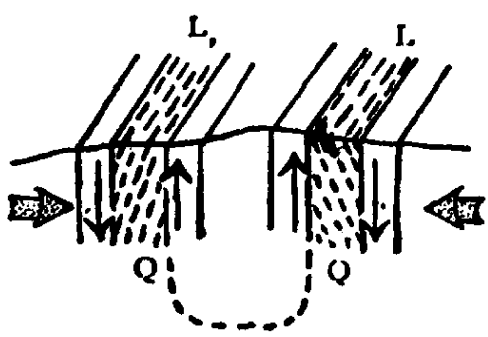

图 6 片麻理在 $\mathrm{Q}$ 面和 $\mathrm{L}$ 面上 与层理的不同关系示意图 斜交.所以片麻理与层理的关系,在辩认褶䏢形迹的作用上 与一般沉积岩地区䢃理与层理的关系具有相似的意义，即 片麻理与层理相交锐角指示邻层相对运动的方向.

3. 线理的成因及测量它的意义我们把矿物在 $S$ 面、 $L$ 面上的定向排列称之为线理. 我们认为,组成线理的 那些变质矿物是在变质作用过程中与褶皱同时生成的. 一 般来说，矿物的长轴方向是其所受压力最小而拉应力最大 的方向. 因此，线理的排列就会严格地受变质作用过程中 作用力的支配. 故它们在各处的产状也就成了反映该处作用力达到平衡状态的忠实记录 (不 包括后期变动). 如果说褶曲两翼形态及其紧密程度, 可以表示水平挤压力的相对大小, 那么 褶皱枢纽的倾伏和起伏则表示垂直方向力的相对大小. 线理产状的起伏，恰与褶曲枢纽的起 伏密切相关,倾向变化与褶曲的开合一致. 而线理的局部变化,往往是局部分力造成的.

基于上述认识,利用线理可以解决或帮助我们分析如下一些问题:

（1）利用线理总体倾伏来判断褶曲的倾伏方向.

(2) 利用线理和褶曲在平面上转折端的关系来区分褶曲形迹. 如转折端在多数线理倾向 一边,为背形褶曲, 反之为向形褶曲. 这办法可以弥补层理被片理掩盖造成的困难.

(3) 利用线理求向斜枢纽起伏和矿体埋深. 自向斜某层转折端始,在轴面经过的位置, 测 条线理产状变化剖面. 再把这些数据整理在笛卡儿坐标系第 IV 象限上, 用极坐标原理, 利用 相邻两点倾角各控制平距之半的办法, 用作图法大略地作出平距与该层枢纽埋藏标高的函数 关系图象. 同理可求矿层标高 (见图 3 中推算矿体). 如果向斜为厢状褶曲, 多作几条函数曲 线,结合两翼矿层产状, 可以大略圈出矿体埋藏等值线图.

（4）利用线理寻找后期构造,方法与片理类似.

有了上述的认识和资料, 就可以对矿区褶皱构造进行分析了. 从图 7 可以看出, 该矿区的 四个矿带被南部小庙沟断层断成了不连续的 “ $\mathrm{W}$ ” 形. 前文所述的几十张层中拖褶皱素描图 主要分布在 II、III、IV 矿带, 且每个矿带由北到南都有. 片麻理斜交层理的关系图, 位于 
II、III 矿带中部内侧附近地层中，出露在冲沟陡坎上. 用本节 1 和 2 中的原理分析每个资

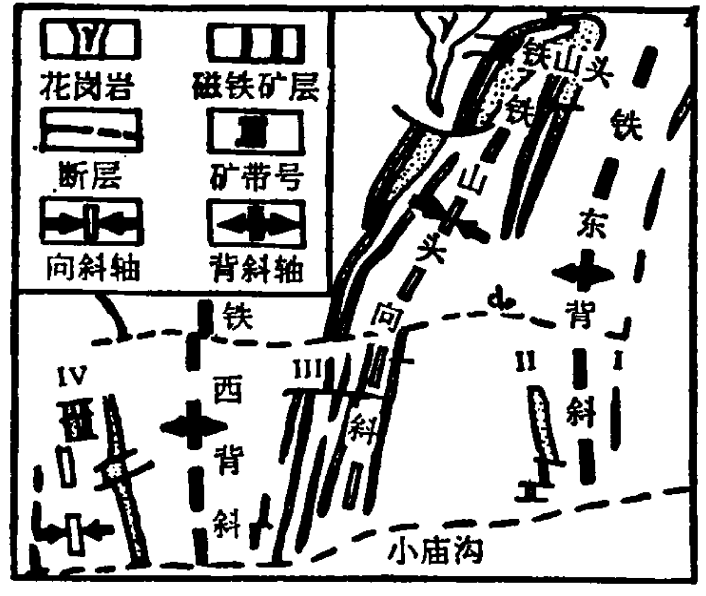

图 7 沙厂铁矿区构造纲要示意图 料，II-III 矿带间的地层相对运动方向都是向上 的, III-IV 矿带间的地层相对运动方 向 都是 向 下的(向东西类推),得出 II-III 矿带间呈向形褶 曲, III-IV 矿带间呈背形褶曲(向东西类推). 又 从线理资料看, II-IV 矿带间的几百线理，除很 少数倾向北 (反映褟皱枢纽局部起伏) 外,绝大多 数（或总体）都倾向南. 用本节 3 (2) 之道理，亦 可得出与上述褶曲同形. 再考虑这些层中拖褶皱 的形态都表明其层间滑动力没有 形成 “绳曲” 强 烈,就否定了超平卧倒转褶皱的可能性,得出了前 文的结论. 这和我们对磁测平面等值线图、平剖 图的解释结论相同. 简言之,因地层走向近南北, (见图 7), 且 $J_{r}>J_{i}$, 磁化方向也近南北, 故可以近似看成垂直磁化. 在 III一IV 矿带间, 磁异 常正负相间,以负为主,显示了背斜核部的矿层被剥蚀后的特征. 而 II-III 矿带间, 正异常值 高, 又平缓稳定, 且其与两矿带一样向南逐渐开阔,再看铁山头,东、西、北三面被高值负异常环 抱, 充分显示了核部存在盲矿的向斜及其内倾转折的特点. 加之,后来在铁山头北部陡坡上又 找到了薄层石英磁铁矿层连接 II-III 两个矿带并呈内倾转折 (图 7 中该层是夸大表示的), 更 坚信了我们当时的结论.

十几年过去了,这些结论终于被实践证实了. 这说明我们上述的认识是有道理的,我们在 前震旦纪变质岩地区所采用的这套工作方法,也是行之有效的.

致谢: 本文承蒙程裕淇、陈光远教授和冯建良的指导, 文中部分资料是陈光远教授保存并提供的. 魏东 岩、周振东、王寒竹、苏扳南同志共同完成矿区地质图. 在此深表感谢.

\section{参文献}

[1] M. P. 毕令斯著,张炳熷等译,构造地质学,地质出版社, 1959 .

[2] 程裕琪等,变质岩的一些基本问题和工作方法,中国工业出版社, 1963.

[3] 地质部地质科学技术情报研究所编, 国外小构造研究, 1965, 156-165. 